\title{
Effects of interleukin-17 on human retinal vascular endothelial cell capillary tube formation in vitro
}

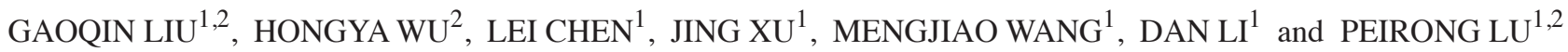 \\ ${ }^{1}$ Department of Ophthalmology, ${ }^{2}$ Jiangsu Clinical Immunology Institute, \\ The First Affiliated Hospital of Soochow University, Suzhou, Jiangsu 215006, P.R. China
}

Received March 28, 2016; Accepted March 10, 2017

DOI: $10.3892 / \mathrm{mmr} .2017 .6623$

\begin{abstract}
The present study aimed to investigate the effect of and mechanism underlying interleukin (IL)-17 on human retinal vascular endothelial cell (HREC) capillary tube formation in vitro. The expression of IL-17 receptor (IL-17R) in human HRECs was quantified using reverse transcriptase-polymerase chain reaction (RT-PCR) and western blot analyses. The roles of IL-17 in HREC migration and capillary tube formation were detected using a wound scratching assay and three-dimensional Matrigel assay, respectively, in vitro. HREC proliferation was examined using a cell counting kit- 8 assay with administration of serial doses of IL-17. The effects of IL-17 on the expression of vascular endothelial growth factor (VEGF), intercellular cell adhesion molecule (ICAM)-1, IL-6 and IL-8 in HRECs were evaluated using RT-PCR and western blot analyses. The results revealed that the HRECs expressed IL-17R, and the number of intact capillary tubes formed by HRECs in the presence of IL-17 was markedly higher, compared with that in the blank control group. The wound scratching assay showed that the numbers of migrated HRECs stimulated with IL-17 at concentrations of 100 or $500 \mathrm{ng} / \mathrm{ml}$ were significantly higher, compared with the number in the control group. The RT-PCR and western blot analyses showed that IL-17 significantly promoted the expression of VEGF, ICAM-1, IL- 6 and IL- 8 by the HRECs. The proliferation of HRECs in the presence of IL-17 was also significantly increased. Therefore, IL-17 increased HREC capillary tube formation through promoting HREC migration, proliferation, and expression levels of VEGF, ICAM-1, IL-6 and IL-8.
\end{abstract}

Correspondence to: Professor Peirong Lu, Department of Ophthalmology, The First Affiliated Hospital of Soochow University, 188 Shizi Street, Suzhou, Jiangsu 215006, P.R. China E-mail: lupeirong@suda.edu.cn

Key words: interleukin-17, vascular, neovascularization, migration, proliferation

\section{Introduction}

Retinal and choroidal vascular diseases can be divided into two groups: Subretinal neovascularization (NV), in which new blood vessels penetrate the outer retina and subretinal space (usually avascular), and retinal vascular diseases, in which the retinal vessels undergo neovascularization or leakage (1). In the retina, new vessels branching off from existing vessels can initially enter the retina. These cases are termed intraretinal microvascular abnormalities (IRMAs) (2). Unlike normal retinal vessels, NV and IRMAs have few tight junctions, and leak plasma into the vitreous gel and surrounding tissue (3). This causes the vitreous gel to contract, degenerate and eventually collapse, which puts pressure on the retina (1). Vitreous hemorrhage and even intact $\mathrm{NV}$ may cause the retina to detach. Traction retinal detachment can involve the macula, which drives and directs vision, causing severe visual loss (4).

The pathogenesis of these vascular diseases have been shown to be associated with hypoxia, chronic inflammation, high levels of angiogenic factors, including stromal cell-derived factor $1-\alpha$, vascular endothelial growth factor (VEGF), and platelet-derived growth factor subunit B (5). In addition, inflammation is reported to contribute substantially to several vascular events, including the development and rupture of atherosclerotic plaques, angiogenesis, ischemia/reperfusion damage, and formation of aortic aneurysms (6). The infiltration of inflammatory cells into the vascular tissues causes the release of proteases, reactive oxygen species and cytokines, and triggers vasoconstriction/vasodilation (7), thrombus formation $(8,9)$, neointimal growth $(10,11)$, tissue remodeling and angiogenesis $(11,12)$.

The interleukin (IL)-17 cytokine family contains six members (IL-17A-F) and at least five receptors (IL-17RA-E), as reported by Moseley et al (13). IL-17, a known pro-inflammatory cytokine exerts several biologic activities, including the induction of prostaglandin E2 (PGE2), IL-6 and IL-8. It also increases the expression of intercellular adhesion molecule (ICAM)-1 in keratinocytes and fibroblasts (14-17), and stimulates the secretion of IL-1 $\beta$, stromelysin and tumor necrosis factor (TNF)- $\alpha$ by macrophages (18). IL-17 receptor (IL-17R) is a type 1 transmembrane protein. It has an unusually long intracellular domain (19). Although the intracellular signaling pathway and pro-inflammatory function of IL-17 are visibly similar to those of Toll and IL-1, IL-17R shares no 
homology with other receptor sequences, thus IL-17, homologous proteins and their viral homologues can be considered a novel cytokine family (20).

Previously, it was reported that IL-17 contributes to tumor angiogenesis by causing the proliferation and migration of these vascular endothelial cells into tissues (21). However, the role of IL-17 in the mediation of retinal neovascularization following severe injury remains to be elucidated. The aim of the present study was to investigate the role of IL-17 in angiogenesis by assessing the effects of IL-17 during different stages of neovascularization, including the proliferation, migration and tube formation of human retinal endothelial cells (HRECs).

\section{Materials and methods}

Reagents and antibodies. The HRECs were purchased from Yaji Biological Technologies (Shanghai, China). Neutralizing mouse anti-human IL-17 antibody (cat. no. NBP2-27338; clone 4H1524) and human recombinant IL-17 protein (cat. no. NBP2-35040-25 $\mu \mathrm{g}$ ) were purchased from Novus Biologicals (Littleton, CO, USA). The cell counting kit- 8 was purchased from Dojindo Molecular Technologies, Inc. (Kumamoto, Japan). Primers were synthesized by Shanghai Sangon Biological Engineering Technology and Service Co., Ltd. (Shanghai, China). Trypsin-EDTA was purchased from Sigma-Aldrich; Merck Millipore (Darmstadt, Germany). Rabbit anti-VEGF antibody (cat. no. sc-152) was purchased from Santa Cruz Biotechnology, Inc. (Santa Cruz, CA, USA). The total RNA extraction kit (RNeasy Mini kit) and reverse transcription kit (Ominiscript RT kit) were purchased from Qiagen Sciences, Inc. (Frederick, MA, USA). Matrigel was purchased from BD Biosciences (Franklin Lakes, NJ, USA). Dulbecco's modified Eagle's medium (DMEM) was purchased from HyClone; GE Healthcare Life Sciences (Logan, UT, USA). Fetal bovine serum was purchased from PAA Laboratories; GE Healthcare Life Sciences). Anti-phosphatidylinositol 3 kinase (PI3K; P110- $\alpha$ ) antibody (cat. no. 611399) was purchased from BD Biosciences (San Jose, CA, USA). Anti-glyceraldehyde 3-phosphate dehydrogenase (GAPDH) antibody (cat. no. AF0006) was purchased from Beyotime Institute of Biotechnology (Shanghai, China).

Cell culture and treatment of HRECs. As described in detail previously (22), the HRECs were cultured at $37^{\circ} \mathrm{C}$ in a humidified atmosphere of $95 \%$ air and $5 \% \mathrm{CO}_{2}$ with DMEM medium containing $10 \%$ fetal bovine serum. The cells were passaged by trypsinization and reseeded at a 1:3 dilution. The HRECs were split at $\sim 90 \%$ confluence and culture media were replaced every 2-3 days.

The HRECs were divided into several groups, as follows: Control group; IL-17 groups, to which specific concentrations of 10, 50,100,200, $500 \mathrm{ng} / \mathrm{ml}$ of recombinant human IL-17 protein (25 $\mu \mathrm{g}$; cat. no. NBP2-35040; Novus Biologicals) were added; and IL-17 antibodies (Abs) groups, to which IL-17 protein $(500 \mathrm{ng} / \mathrm{ml})$ was combined with neutralizing anti-human IL-17 antibody $(0.5 \mathrm{mg} / \mathrm{ml}$, at a 1:1,100 dilution; cat. no. NBP2-27338; Novus Biologicals). The HRECs were split at $\sim 90 \%$ confluence and subcultured in either 6 -well or 96-well plates and incubated at $37^{\circ} \mathrm{C}$ with the protein and the antibody for either $12 \mathrm{~h}$ or $24 \mathrm{~h}$ depending on the assay conditions.

Tube formation assay. A morphogenesis assay was performed on Matrigel for assessment of the effect of IL-17 on the HRECs. The assay was performed according to the procedure described in detail previously (23). The Matrigel was placed overnight in a $4^{\circ} \mathrm{C}$ refrigerator to thaw. Subsequently $60 \mu \mathrm{l}$ of Matrigel was immediately placed onto a pre-cooled 96-well plate, which was placed for $30 \mathrm{~min}$ in a humidified $\mathrm{CO}_{2}$ incubator at $37^{\circ} \mathrm{C}$ for Matrigel to solidify. The HRECs, following culture in different media in the presence or absence of IL-17, were immediately seeded onto the solid Matrigel at a density of $1.5 \times 10^{4}$ cells per well. These plates were then placed at $37^{\circ} \mathrm{C}$ in a humidified atmosphere of $95 \%$ air and $5 \% \mathrm{CO}_{2}$ for $12 \mathrm{~h}$ to allow the capillary-like structures to form. Angiogenesis, the formation of capillary tubes, was assessed following $12 \mathrm{~h}$ of cultivation. The tube-like capillary structures were examined under an Olympus TMS inverted phase contrast microscope (Olympus Corporation, Tokyo, Japan). The micrographs were captured using an Olympus digital camera.

Cell migration assay. As described in detail previously (23), wound scratch assays were performed to assess the effects of IL-17 on the migration of HRECs. This type of assay is inexpensive and simple, and the experimental conditions can be modified as required. After $24 \mathrm{~h}$, the cells were seeded into 6-well plates at a density of $2.5 \times 10^{5}$ cells/well reaching $70-80 \%$ confluence in a monolayer. The monolayer was slowly and gently scratched perpendicularly with an unused $1 \mathrm{ml}$ pipette tip across the center of the well. The gap was equal to the outer diameter of the end of the micropipette tip. Following the scratch induction, the wells were washed with medium twice gently to remove any detached cells. Fresh medium was then added to the wells. In the experimental wells, the cells were treated with human recombinant IL-17 protein or IL-17 Abs, whereas the control wells were treated with PBS. The cells were grown at $37^{\circ} \mathrm{C}$ for $48 \mathrm{~h}$, during which images were captured under an Olympus TMS inverted phase contrast microscope (Olympus Corporation, Tokyo, Japan) at 0, 12, 24 and $48 \mathrm{~h}$. The length of the gap was evaluated quantitatively using ImageJ software version 2.1.4.7 (http://rsb.info.nih. gov/ij/download.html). Each assessment of each experimental group was repeated several times.

Cell proliferation assay. As described in detail previously (24), cell proliferation was analyzed using a CCK-8 assay (Dojindo Molecular Technologies, Inc., Kumamoto, Japan). This kit measures the metabolic activity of dehydrogenases using a tetrazolium salt. When dehydrogenases are present, the tetrazolium salt produces a water-soluble, yellow formazan. The quantity of formazan produced is proportional to the number of living cells. It was measured using a thermo multi-scan EX plate reader (Thermo Multiskan EX plate reader; Thermo Fisher Scientific, Inc., Waltham, MA, USA) The absorbance was measured $24 \mathrm{~h}$ following attachment of the HRECs to the plate and stimulation with IL-17 protein or anti-IL-17 neutralizing antibody. The inhibition rate (IR) of the proliferation of cells in the groups were compared with the control groups. 
Table I. Sequences of the primers used for reverse transcription-polymerase chain reaction analysis.

\begin{tabular}{|c|c|c|c|c|}
\hline \multicolumn{2}{|c|}{ Primer Sequence $\left(5^{\prime} \rightarrow 3^{\prime}\right)$} & \multirow{2}{*}{$\frac{\text { Product size }(\mathrm{bp})}{241}$} & \multirow{2}{*}{$\begin{array}{c}\text { Annealing temperature }\left({ }^{\circ} \mathrm{C}\right) \\
57\end{array}$} & \multirow{2}{*}{$\frac{\text { Cycles (n) }}{37}$} \\
\hline IL-17R & $\begin{array}{ll}\text { F: } & \text { TTGCTTTGAGCACATGCACC } \\
\text { R: } & \text { GAACCAGTACACCCACAGGG }\end{array}$ & & & \\
\hline VEGF & $\begin{array}{ll}\text { F: } & \text { TGGTCCCAGGCTGCACCCAT } \\
\text { R: } & \text { CGCATCGCATCAGGGGCACA }\end{array}$ & 509 & 57 & 37 \\
\hline IL-1 $\beta$ & $\begin{array}{ll}\text { F: } & \text { CCACCTCCAGGGACAGGATA } \\
\text { R: } & \text { AACACGCAGGACAGGTACAG }\end{array}$ & 132 & 57 & 36 \\
\hline IL-6 & $\begin{array}{ll}\text { F: AGTGAGGAACAAGCCAGAGC } \\
\text { R: AGCTGCGCAGAATGAGATGA }\end{array}$ & 500 & 57 & 37 \\
\hline IL-8 & $\begin{array}{ll}\text { F: } & \text { GGTGCAGTTTTGCCAAGGAG } \\
\text { R: } & \text { TTCCTTGGGGTCCAGACAGA }\end{array}$ & 176 & 60 & 37 \\
\hline ICAM-1 & $\begin{array}{l}\text { F: CCAGGAGACACTGCAGACAG } \\
\text { R: CTTCACTGTCACCTCGGTCC }\end{array}$ & 100 & 60 & 37 \\
\hline GAPDH & $\begin{array}{l}\mathrm{F}: \text { ACCACAGTCCATGCCATCAC } \\
\mathrm{R}: \text { TCCACCACCCTGTTGCTGTA }\end{array}$ & 452 & 57 & 25 \\
\hline
\end{tabular}

F, forward primer; R, reverse primer; IL, interleukin; IL-17R, IL-17 receptor; VEGF, vascular endothelial growth factor; ICAM, intercellular cell adhesion molecule; GAPDH, glyceraldehyde3-phosphate dehydrogenase.

Semi-quantitative reverse transcription-polymerase chain reaction $(R T-P C R)$ analysis. RT-PCR analysis was performed as described in detail previously (25). Total RNAs were extracted from the HRECs using an RNeasy Mini kit (Qiagen, Inc.). The RNA preparations were then treated with ribonuclease-free deoxyribonuclease I (Thermo Fisher Scientific, Inc.) to remove genomic DNA. Subsequently, $2 \mu \mathrm{g}$ of total RNA was reverse-transcribed at $42^{\circ} \mathrm{C}$ for $1 \mathrm{~h}$ in a $20 \mu \mathrm{l}$ reaction mixture with hexanucleotide random primers and mouse moloney leukemia virus reverse transcriptase (Qiagen, Inc.). Subsequently, serial 4-fold dilution of cDNA was amplified for GAPDH (Table I) and the level of transcribed cDNA was estimated. Equal quantities of $2 \mu \mathrm{l}$ of the cDNA products, $2.5 \mu \mathrm{l}$ of buffer, $1 \mu \mathrm{l}$ of forward primer and $1 \mu \mathrm{l}$ of reverse primer $(20 \mu \mathrm{M} / \mathrm{ml}$; GeneScript, Nanjing, China), $2 \mu \mathrm{l}$ of dNTP Mixture and $0.125 \mu \mathrm{l}$ of TaKaRa Taq ${ }^{\mathrm{M}}$ (5 U/ $\mu$, cat. no. DR100A; TaKaRa Bio, Inc., Kusatsu, Japan) in a final volume of $25 \mu \mathrm{l}$ were then amplified for identification of the target genes. Amplification was performed using a GeneAmp ${ }^{\circledR}$ PCR System 9700 (Perkin-Elmer, Foster City, CA, USA) as follows: Denaturation at $94^{\circ} \mathrm{C}$ for $2 \mathrm{~min}$, and the necessary number of cycles of $94^{\circ} \mathrm{C}$ for $30 \mathrm{sec}, 55-58^{\circ} \mathrm{C}$ for $35 \mathrm{sec}, 72^{\circ} \mathrm{C}$ for $35 \mathrm{sec}$, and a final extension step at $72^{\circ} \mathrm{C}$ for $10 \mathrm{~min}$ (Table I). These PCR products were fractionated on a $1.0 \%$ agarose gel and visualized using ethidium bromide. The intensities of the bands were determined and their ratios to GAPDH determined using ImageJ version 2.1.4.7.

Western blot analysis. As described in detail previously (22), the HRECs were split at $90 \%$ confluence, and were cultured at $37^{\circ} \mathrm{C}$ in a humidified atmosphere of $95 \%$ air and $5 \% \mathrm{CO}_{2}$ in media, with or without IL-17 or IL-17 Abs, for $24 \mathrm{~h}$. After $24 \mathrm{~h}$, the cells were harvested using $0.25 \%$ Trypsin-EDTA, washed three times with cold PBS, and centrifuged at $4^{\circ} \mathrm{C}$ for $5 \mathrm{~min}$ at $1,200 \mathrm{x} \mathrm{g}$. The supernatant was discarded and lysed in $150 \mathrm{ml}$ lysis buffer $(10 \mathrm{mM} \mathrm{KCl}, 20 \mathrm{mM}$ imidazole $\mathrm{HCl}, 10 \mathrm{mM}$ EGTA, $1 \mathrm{mM} \mathrm{MgCl}, 10 \mathrm{mM} \mathrm{NaF}, 1 \%$ Triton, $1 \mathrm{mM}$ EDTA and $1 \mathrm{mM}$ sodium molybdate) at $\mathrm{pH} 6.8$, to which a protease inhibitor cocktail was added (Boehringer Mannheim, Indianapolis, IN, USA) and then sonicated. The lysate was centrifuged at $4^{\circ} \mathrm{C}$ at $9,600 \times \mathrm{g}$ for $15 \mathrm{~min}$. The samples, quantified using NanoDrop 2000UV-Vis spectrophotometer (20 $\mu \mathrm{g} /$ each lane; Thermo Fisher Scientific, Inc.) were boiled for $5 \mathrm{~min}$ and separated using $12.5 \%$ SDS-polyacrylamide gel electrophoresis under denaturing conditions. It was then electroblotted onto a polyvinylidene difluoride membrane (Bio-Rad Laboratories, Inc., Hercules, CA, USA). These membranes were then blocked with $\mathrm{PBS} / 5 \%$ nonfat dry milk for nonspecific binding. Finally, thee membranes were incubated at room temperature (RT) for $1 \mathrm{~h}$ with the following antibodies: Anti-VEGF (cat. no. sc-152; 1:200 dilution; Santa Cruz Biotechnology, Inc.), anti-IL-6 (cat. no. sc-7920; 1:200 dilution; Santa Cruz Biotechnology, Inc.), anti-IL-8 (cat. no. sc-7922; 1:200 dilution; Santa Cruz Biotechnology, Inc.), anti-ICAM (cat. no. sc-7891; 1:200 dilution; Santa Cruz Biotechnology, Inc.) and anti-PIK3 (cat. no. 611399; 1:500 dilution; BD Biosciences) antibodies. The immunoblot assays were then washed with PBST and incubated at room temperature for $1 \mathrm{~h}$ with a horseradish peroxidase-labeled secondary antibody (cat. no. RPN4301 or RPN4201; at a 1:5,000 dilution; Amersham; GE Healthcare Life Sciences, Chalfont, UK). Enhanced chemiluminescence was used to visualize the blots (ECL Plus; Amersham; GE Healthcare Life Sciences) according to the manufacturer's protocol. The intensities of the protein bands were determined and their ratios to GAPDH using ImageJ software, version 2.1.4.7.

Statistical analysis. All data are expressed as the mean \pm standard error of the mean. Data were analyzed statistically as described in detail previously (26), using one-way analysis of variance or two-tailed Student's t-test with statistical software 
(SPSS 18.0; SPSS, Inc., Chicago, IL, USA). P $<0.05$ was considered to indicate a statistically significant difference.

\section{Results}

Expression of IL-17R in HRECs. The mRNA and protein expression levels of IL-17R were detected in the HRECs. The observation of the expression of IL-17R in the HRECs suggested the possible involvement of IL-17/IL-17R interactions in the biological function of the HRECs (Fig. 1).

Effects of IL-17 on tube formation of HRECs. To determine whether IL-17 was involved in the process of tube formation of HRECs, the HREC cells were grown in 96-well plates coated with Matrigel. Following $12 \mathrm{~h}$ of incubation, the cells formed tubes, which showed that the HREC cells incubated with IL-17 exhibited increased tube formation, compared with cells in the control (Fig. 2). Tube formation was quantified, and the results of the statistical analysis indicated that IL-17 promoted tube formation.

Effects of IL-17 on the proliferation of HRECs. To evaluate the effects of IL-17 on the biological function of the HRECs, the role of IL-17 in HREC proliferation was examined in vitro. In the presence of IL-17 or anti-IL-17 antibody, the HRECs were incubated for $24 \mathrm{~h}$, following which cell viability was examined. The proliferation rates of HRECs incubated with IL-17 were higher, compared with that of cells in the control, whereas the HRECs incubated with anti-human IL-17 Abs following preconditioning with IL-17 protein exhibited a significant reduction in cell proliferation, compared with the 100 or 500 IL-17 groups (Fig. 3). The quantification of optical density (OD) values and statistical analysis of IR demonstrated that IL-17 had the ability to promote cell proliferation, however, the anti-IL-17 antibody prevented this promotion. These data suggested that the enhancement in the proliferation of HRECs following IL-17 treatment was responsible for the effect of IL-17 on the promotion of HREC tube formation in vitro.

Effects of IL-17 on cell migration. The effects of IL-17 on HREC migration have not been reported previously. To evaluate whether IL-17 affected the process of HREC migration, an in vitro scratch wound assay was performed to evaluate the migration ability of HRECs under different concentrations of IL-17 or IL-17 antibody. As shown in Fig. 4A, compared with the control group, wound closure was significantly accelerated in the group treated with IL-17, and the wound was almost closed at $24 \mathrm{~h}$ post-injury. However, in the IL-17 antibody-treated group, the wound area remained wide following preconditioning with IL-17 protein at $24 \mathrm{~h}$. The migration distance of HRECs was quantified, as shown in Fig. 4B. These data showed that IL-17 effectively promoted the migration ability of HRECs.

Enhanced expression of angiogenic factors and PI3K molecules in IL-17-treated HRECs. In various situations, the outcome of angiogenic processes is determined by the balance between anti-angiogenic and angiogenic factors (27). In the present study, the gene and protein expression of angiogenic factors in HRECs were detected. Among the angiogenic-associated factors,
A

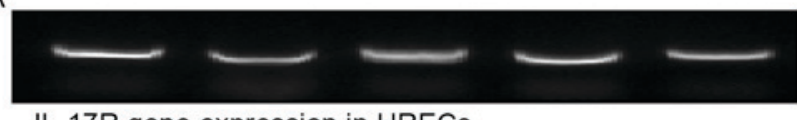

B

IL-17R gene expression in HRECs

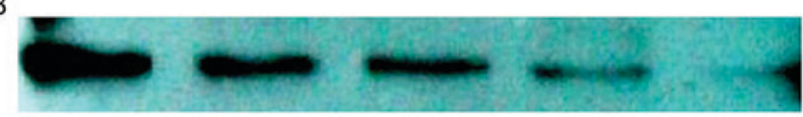

IL-17R protein expression in HRECs

Figure 1. mRNA and protein expression of IL-17R in HRECs (A) Semi-quantitative RT-PCR analysis was used to evaluate the mRNA expression of IL-17R. HRECs were harvested to extract total RNAs and RT-PCR analysis was performed using the obtained total RNAs. (B) Western blot analysis was performed to evaluate protein expression of IL-17R. HRECs were harvested to extract the total protein ( $n=5)$. IL-17R, interleukin 17 receptor; HRECs, human retinal endothelial cells; RT-PCR, reverse transcription-polymerase chain reaction.

A

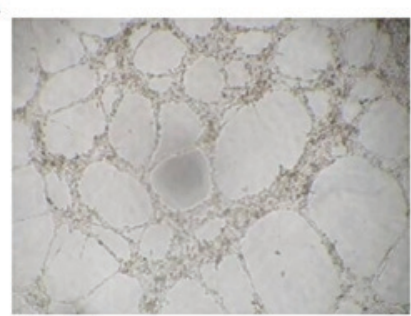

Control

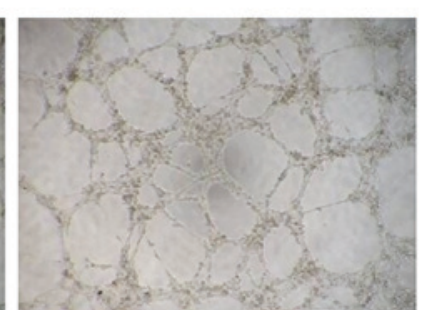

IL-17

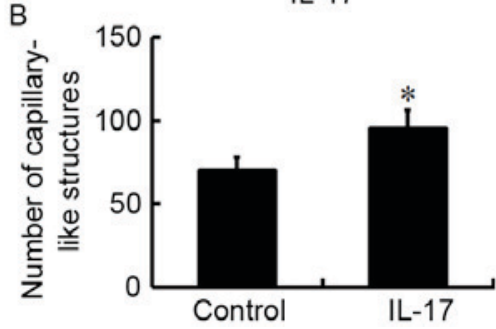

Figure 2. Effect of IL-17 on the tube formation of human retinal endothelial cells. (A) Tube formation assays showed that IL-17 significantly promoted the formation of capillary-like structures (magnification, x200). (B) Quantitative data of the numbers of capillary-like structures from three independent experiments. Data are presented as the mean \pm standard error of the mean $(\mathrm{n}=3) .{ }^{*} \mathrm{P}<0.05$, compared with the control. IL-17, interleukin-17.

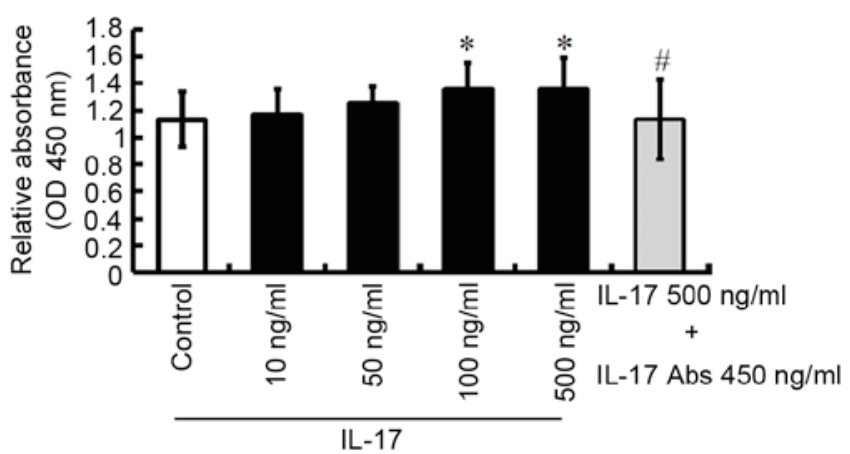

Figure 3. Effect of IL-17 on the proliferation of HRECs. The results of the cell counting kit- 8 assays revealed that cell proliferation in the IL-17 groups were significantly enhanced, compared with that in the control. However, the proliferation of HRECs was significantly suppressed in the IL-17 Abs group, compared with that in the IL-17 group. Data are presented as the mean \pm standard error of the mean $(n=3)$. ${ }^{*} \mathrm{P}<0.05$, compared with the control; ${ }^{\text {"P}} \mathrm{P}<0.05$, compared with the 100 or $500 \mathrm{ng} / \mathrm{ml} \mathrm{IL}-17$ groups. HRECs, human retinal endothelial cells; IL-17, interleukin-17; Abs, antibodies; OD, optical density. 

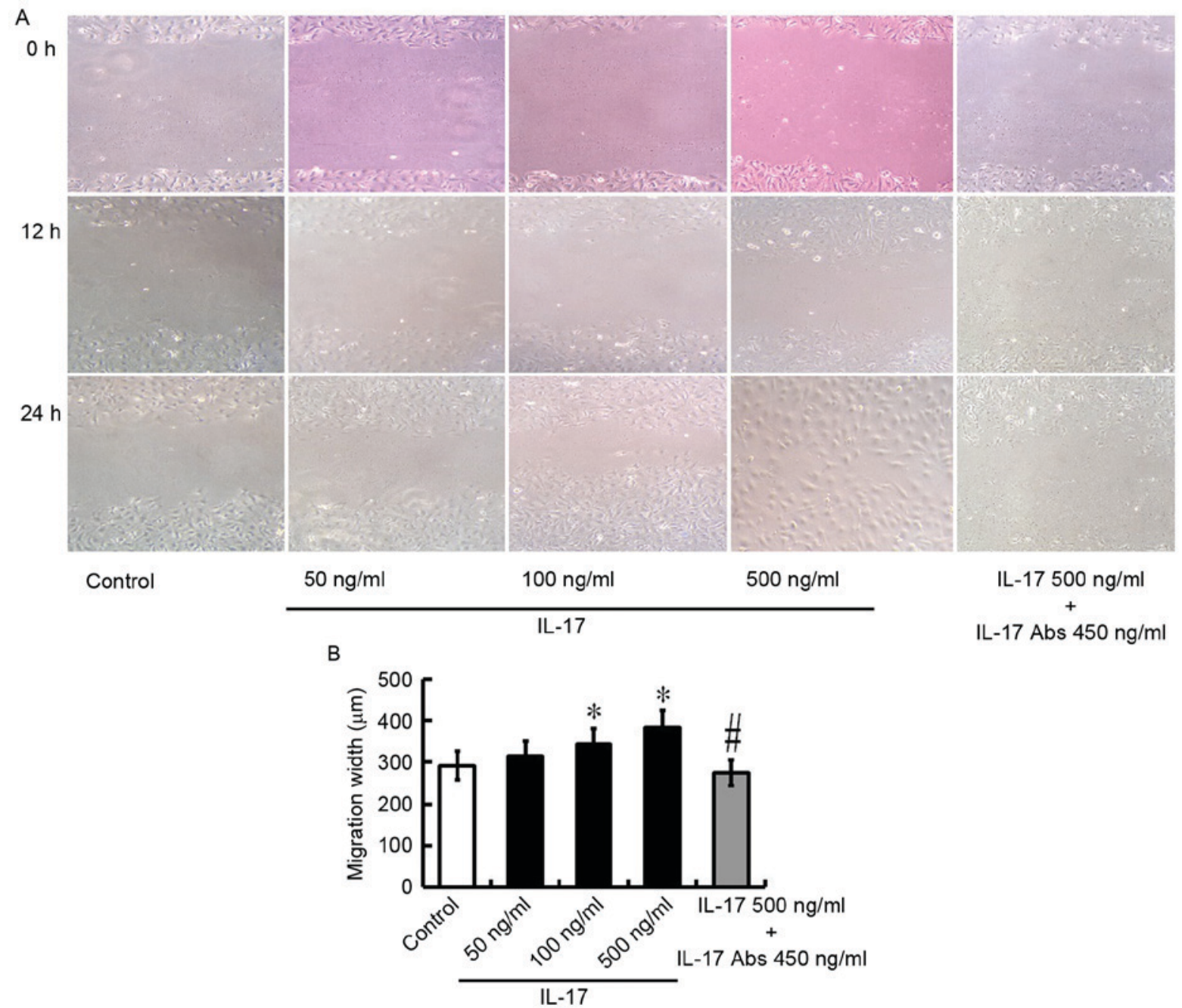

Figure 4. Effect of IL-17 on the migration of HRECs. (A) Results of the scratch wound assay showed that IL-17 enhanced HREC migration, whereas HREC migration was suppressed by IL-17 Abs. Image of the re-endothelialized monolayer area (magnification, $x 200$ ). (B) Quantitative data of the migration distance from three independent experiments. All values are presented as the mean \pm standard error of the mean $(\mathrm{n}=3)$. ${ }^{*} \mathrm{P}<0.05$, compared with the control; ${ }^{*} \mathrm{P}<0.05$, compared with the $500 \mathrm{ng} / \mathrm{ml}$ IL-17 group. HRECs, human retinal endothelial cells; IL-17, interleukin-17; Abs, antibodies.

including VEGF, IL-8, IL-6, IL-1 $\beta$ and ICAM-1, which were detected, the gene expression levels of VEGF, IL-6, IL-8 and ICAM-1 were higher in the IL-17 treated cells, compared with those in the control groups (Fig. 5). Western blot analysis of the protein expression of VEGF, ICAM-1, IL- 6 and IL- 8 revealed that VEGF, ICAM-1, IL-6 and IL-8 were also increased following treatment with IL-17, compared with the vehicle-treatment cells (Fig. 6). These results indicated that IL-17 may promote HREC tube formation, migration and proliferation via promoting angiogenesis by enhancing the expression of the angiogenic factors, including VEGF, ICAM-1, IL-6 and IL-8.

The expression of PI3K in HRECs was also examined in the present study. The activation of PI3K is an integral component of the VEGF signaling pathway and promotes endothelial migration (28). The present study aimed to determine whether IL-17 affected cell migration through the activation of PI3K in HRECs. It was found that the expression of PI3K was increased in the IL-17-treated mice (Fig. 7). This result suggested that IL-17 induced the activation of PI3K via the expression of VEGF. The detection of PI3K confirmed that PI3K was activated in the cells depending on the expression of VEGF, which was attributed to the regulation of IL-17.

\section{Discussion}

To the best of our knowledge, results on the role of IL-17 in angiogenesis remain contradictory. In mice, tumor growth and lung metastasis were reported to be increased in IL-17-deficient mice (29), suggesting that IL-17 inhibited tumor development and neovascularization. However, there is also evidence demonstrating that IL-17 promotes the production of pro-angiogenic factors, including nitric oxide, hepatocyte growth factor (HGF), chemokine (C-X-C motif) ligand (CXCL1)/KC, CXCL2/MIP-2, PGE1, PGE2 and VEGF by rheumatoid arthritis synovial fibroblasts, and the production of a number of these factors is further enhanced by TNF- $\alpha$ (30). Of note, there are data revealing that IL-17 alone is unable to induce angiogenesis, but can indirectly mediate human microvascular endothelial cell growth by promoting the mitogenic activity of HGF, basic fibroblast growth factor (bFGF) and VEGF $(31,32)$. However, the effects of IL-17 on ocular neovascularization require further investigation. The present study examined HRECs and found that the IL-17R gene and protein were expressed in HRECs, and that the stimulation of recombinant human IL-17 protein had significant 

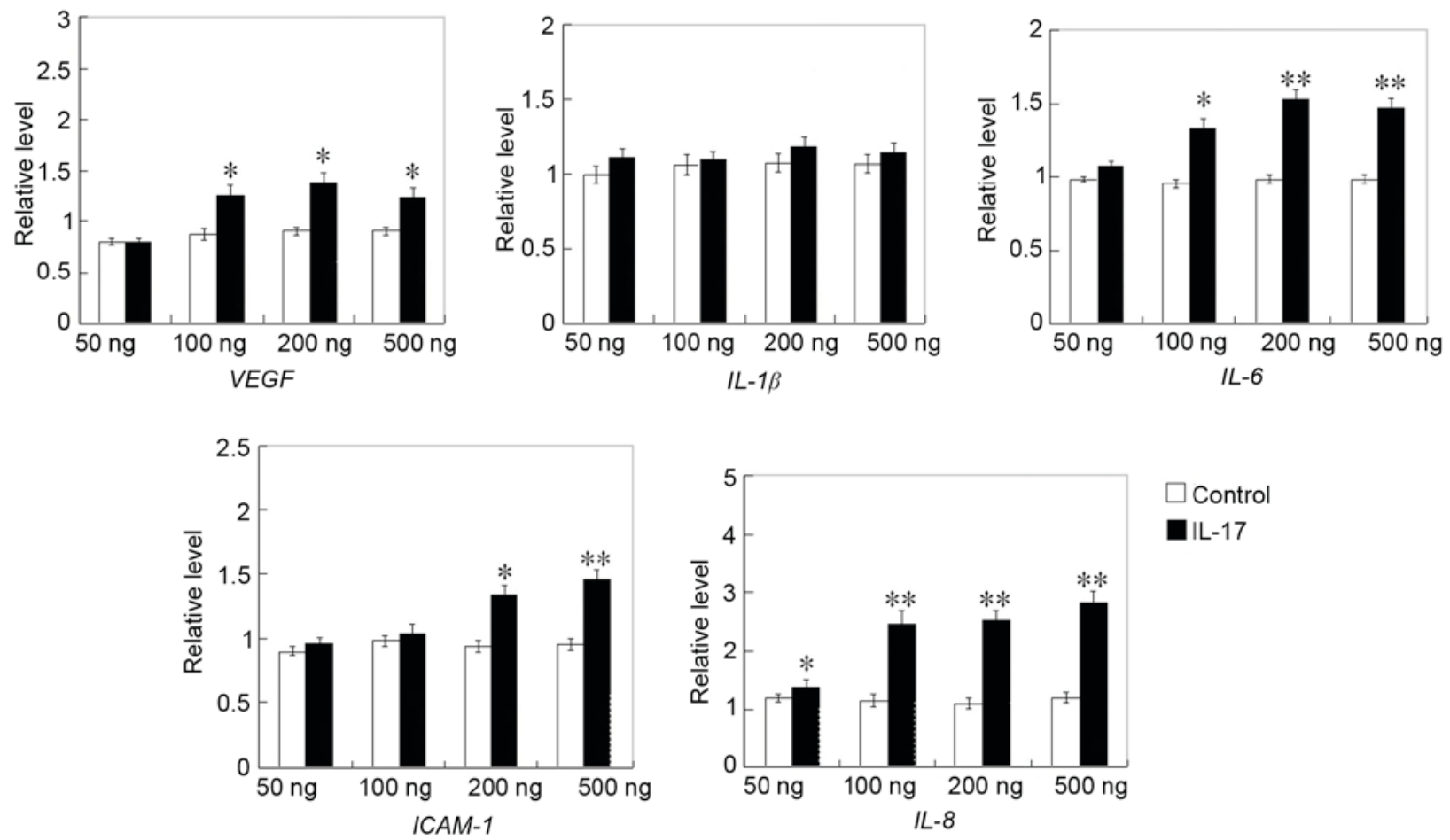

Figure 5. Effect of IL-17 on angiogenic gene expression of human retinal endothelial cells. Ratios of VEGF, IL-1 $\beta$, IL-6, IL-8 and ICAM-1 to GAPDH in the control group and IL-17 groups were determined using reverse transcription-polymerase chain reaction analysis. All values are presented as the mean \pm standard error of the mean $(n=3)$. $P<0.05$ and ${ }^{* *} \mathrm{P}<0.01$, compared with the control. IL, interleukin; VEGF, vascular endothelial growth factor; ICAM- 1 , intercellular cell adhesion molecule-1; GAPDH, glyceraldehyde 3-phosphate dehydrogenase.

A

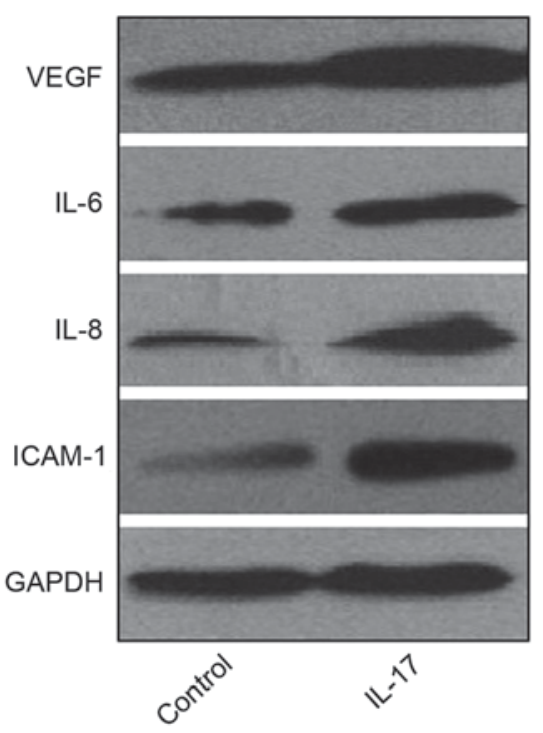

B
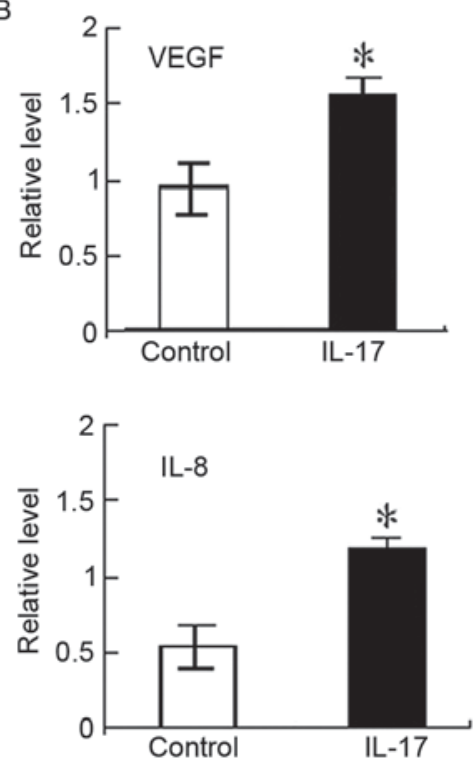
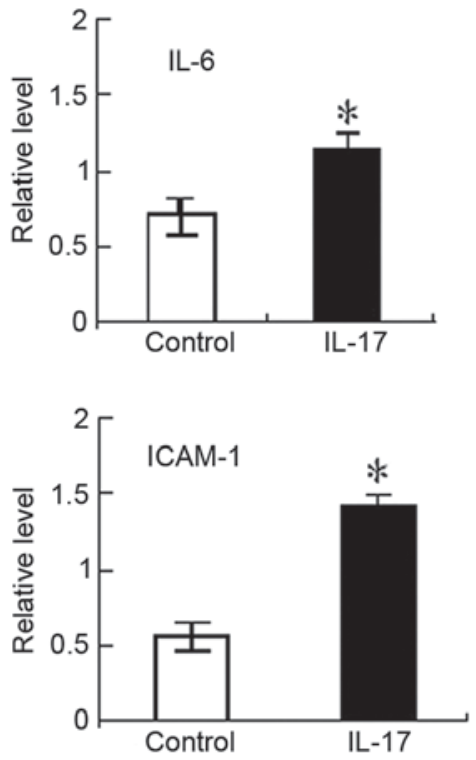

Figure 6. Effect of IL-17 on angiogenic protein expression of human retinal endothelial cells. (A) Protein extracts were obtained and subjected to western blot analysis. Representative results from three independent experiments are shown. (B) Ratios of VEGF, IL-6, IL-8 and ICAM-1 to GAPDH protein bands in the control and IL-17 groups were determined. All values are presented as the mean \pm standard error of the mean ( $\mathrm{n}=6-8$ animals). "P $<0.05$, compared with the control. IL-17, interleukin-17; VEGF, vascular endothelial growth factor; ICAM, intercellular cell adhesion molecule; GAPDH, glyceraldehyde 3-phosphate dehydrogenase.

capillary tube formation-promoting effects. It is reasonable to suggest that IL-17 had the potential to promote the capillary tube formation of HRECs in vitro.

As is already known, angiogenic factors, including bFGF and VEGF, have potent efficacy in stimulating blood vessel formation (33). The process of angiogenesis is tightly regulated by a series of pro- and anti-angiogenic molecules in normal physiology, and disruption of this balance can cause serious consequences, including neovascularization (34). These factors are exacerbated by various cells, including fibroblasts, macrophages and neutrophils, and by vascular endothelial cells themselves (35). In the present study, the gene and protein 
A

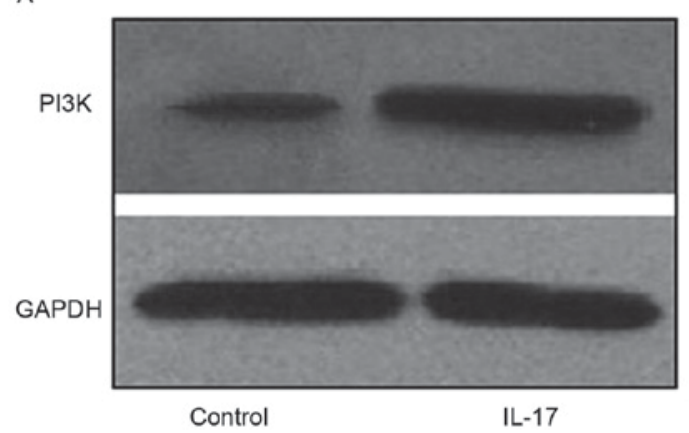

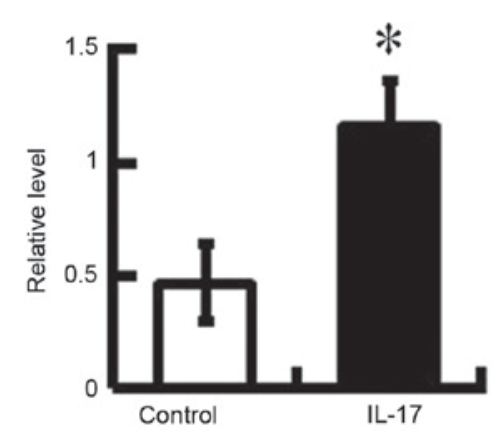

Figure 7. Effect of IL-17 on protein expression of the PI3K pathway. (A) Representative results from three independents western blot assays. The western blot analysis showed that IL-17 significantly increased the protein expression of the PI3K pathway. (B) Quantitative data of the ratio from three independent experiments. All values are presented as the mean \pm standard error of the mean $(\mathrm{n}=3)$. ${ }^{*} \mathrm{P}<0.05$, compared with the control. PI3K, phosphatidylinositol 3 kinase; IL-17, interleukin-17; GAPDH, glyceraldehyde 3-phosphate dehydrogenase.

expression levels of ICAM-1, IL-1 $\beta$, IL-6, IL-8 and VEGF were detected in HRECs. It was found that the expression levels of ICAM-1, IL-6, IL-8 and VEGF in the IL-17-treated cells were significantly upregulated. This indicated that IL-17 may be involved in the process of angiogenesis by skewing the balance towards pro-angiogenesis, and thereby causing NV $(36,37)$.

The angiogenic cascade is a complex and multi-step process, with endothelial cell migration and proliferation as the initial step in angiogenesis, followed by endothelial cell differentiation into a capillary-like network (38). In the present study, it was found that IL-17 had the ability to promote HREC migration and proliferation in a dose-dependent manner. Compared with the recombinant human IL-17 protein-treated groups, treatment with IL-17 combined with neutralizing anti-human IL-17 Abs suppressed the migration and proliferation of HRECs. These results are consistent with those of a previous report (39), suggesting that IL-17 exerted angiogenic effects on HRECs.

To further examine the mechanisms underlying the IL-17-induced mediation of HREC capillary tube formation, the role of IL-17 on the signal expression of PI3K/Akt was evaluated. The process of angiogenesis is associated with several signaling pathways. The activation of PI3K/Akt in endothelial cells is a crucial intracellular signaling step for angiogenesis (40). Several growth factors, including bFGF and VEGF, induce angiogenesis through the activation of these kinases $(41,42)$. In the present study, it was found that IL-17 promoted the expression of active phosphorylated PI3K (43). This suggested that IL-17 had a pro-angiogenic effect via regulating the expression of VEGF through the activation of PI3K/Akt.

In conclusion, the present study demonstrated a novel biologic function for IL-17 on HRECs. It promoted HREC capillary tube formation by promoting cell proliferation and migration. These effects may have occurred through enhancing the expression of cytokines, including VEGF and ICAM-1, and inducing the production of several pro-angiogenic factors, leading to an imbalance between the activators and inhibitors of angiogenesis present within the vascular microenvironment. These findings indicate the potential of the effect of IL-17 on angiogenesis, which may assist in future clinical treatment.

\section{Acknowledgements}

The present study was supported by the National Natural Science Foundation in China (grant no. 31600736), the Jiangsu Province's Key Provincial Talents Program (grant no. RC2011104), the Soochow Scholar Project of Soochow University (grant no. R5122001 to Professor Peirong Lu), the Natural Science Foundation of Jiangsu Province of China (grant no. BK20151208) and the Suzhou Municipal Natural Science Foundation (grant no. SYS201448 to Dr Gaoqin Liu).

\section{References}

1. Campochiaro PA: Ocular neovascularization. J Mol Med (Berl) 91: 311-321, 2013

2. Lee CS, Lee AY, Sim DA, Keane PA, Mehta H,Zarranz-Ventura J, Fruttiger M, Egan CA and Tufail A: Reevaluating the definition of intraretinal microvascular abnormalities and neovascularization elsewhere in diabetic retinopathy using optical coherence tomography and fluorescein angiography. Am J Ophthalmol 159: 101-110.e1, 2015

3. Ida $\mathrm{H}$, Tobe $\mathrm{T}$, Nambu $\mathrm{H}$, Matsumura M, Uyama $\mathbf{M}$ and Campochiaro PA: RPE cells modulate subretinal neovascularization, but do not cause regression in mice with sustained expression of VEGF. Invest Ophthalmol Vis Sci 44: 5430-5437, 2003.

4. Teke MY, Balikoglu-Yilmaz M, Yuksekkaya P, Citirik M, Elgin U, Kose T and Ozturk F: Surgical outcomes and incidence of retinal redetachment in cases with complicated retinal detachment after silicone oil removal: Univariate and multiple risk factors analysis. Retina 34: 1926-1938, 2014.

5. Praidou A, Androudi S, Brazitikos P, Karakiulakis G, Papakonstantinou E and Dimitrakos S: Angiogenic growth factors and their inhibitors in diabetic retinopathy. Curr Diabetes Rev 6: 304-312, 2010.

6. Sullivan GW, Sarembock IJ and Linden J: The role of inflammation in vascular diseases. J Leukoc Biol 67: 591-602, 2000.

7. Peitzman AB, Billiar TR, Harbrecht BG, Kelly E, Udekwu AO and Simmons RL: Hemorrhagic shock. Curr Probl Surg 32: 925-1002, 1995.

8. Lassila R: Inflammation in atheroma: Implications for plaque rupture and platelet-collagen interaction. Eur Heart J 14 (Suppl K): 94-97, 1993.

9. Nielsen JD: The effect of antithrombin on the systemic inflammatory response in disseminated intravascular coagulation. Blood Coagul Fibrinolysis 9 (Suppl 3): 11-15, 1998.

10. Hansson GK: Immunological control mechanisms in plaque formation. Basic Res Cardiol 89 (Suppl 1): 41-46, 1994.

11. Wilensky RL, March KL, Gradus-Pizlo I, Sandusky G, Fineberg $\mathrm{N}$ and Hathaway DR: Vascular injury, repair, and restenosis after percutaneous transluminal angioplasty in the atherosclerotic rabbit. Circulation 92: 2995-3005, 1995. 
12. Mach F, Schonbeck U, Fabunmi RP, Murphy C, Atkinson E, Bonnefoy JY, Graber P and Libby P: T lymphocytes induce endothelial cell matrix metalloproteinase expression by a CD40L-dependent mechanism: Implications for tubule formation. Am J Pathol 154: 229-238, 1999.

13. Moseley TA, Haudenschild DR, Rose L and Reddi AH: Interleukin-17 family and IL-17 receptors. Cytokine Growth Factor Rev 14: 155-174, 2003.

14. Yao Z, Fanslow WC, Seldin MF, Rousseau AM, Painter SL, Comeau MR, Cohen JI and Spriggs MK: Herpesvirus Saimiri encodes a new cytokine, IL-17, which binds to a novel cytokine receptor. Immunity 3: 811-821, 1995.

15. Fossiez F, Djossou O, Chomarat P, Flores-Romo L, Ait-Yahia S, Maat C, Pin JJ, Garrone P, Garcia E, Saeland S, et al: T cell interleukin-17 induces stromal cells to produce proinflammatory and hematopoietic cytokines. J Exp Med 183: 2593-2603, 1996.

16. Yao Z, Painter SL, Fanslow WC, Ulrich D, Macduff BM, Spriggs MK and Armitage RJ: Human IL-17: A novel cytokine derived from T cells. J Immunol 155: 5483-5486, 1995.

17. Aarvak T, Chabaud M, Miossec P and Natvig JB: IL-17 is produced by some proinflammatory Th1/ Th0 cells but not by Th2 cells. J Immunol 162: 1246-1251, 1999.

18. Jovanovic DV, Di Battista JA, Martel-Pelletier J, Jolicoeur FC, He Y, Zhang M, Mineau F and Pelletier JP: IL-17 stimulates the production and expression of proinflammatory cytokines, IL-beta and TNF-alpha, by human macrophages. J Immunol 160: 3513-3521, 1998.

19. Numasaki M, Fukushi J, Ono M, Narula SK, Zavodny PJ, Kudo T, Robbins PD, Tahara $\mathrm{H}$ and Lotze MT: Interleukin-17 promotes angiogenesis and tumor growth. Blood 101: 2620-2627, 2003.

20. Chang SH, Park H and Dong C: Act1 adaptor protein is an immediate and essential signaling component of interleukin-17 receptor. J Biol Chem 281: 35603-35607, 2006.

21. Suryawanshi A, Veiga-Parga T, Reddy PB, Rajasagi NK and Rouse BT: IL-17A differentially regulates corneal vascular endothelial growth factor (VEGF)-A and soluble VEGF receptor 1 expression and promotes corneal angiogenesis after herpes simplex virus infection. J Immunol 188: 3434-3446, 2012.

22. Chen Z, Liu G, Xiao Y and Lu P: Adrenomedullin22-52 suppresses high-glucose-induced migration, proliferation, and tube formation of human retinal endothelial cells. Mol Vis 20 : 259-269, 2014.

23. Liu G, Zhang W, Xiao Y and Lu P: Critical role of IP-10 on reducing experimental corneal neovascularization. Curr Eye Res 40: 891-901, 2015.

24. Chao TI, Xiang S, Chen CS, Chin WC, Nelson AJ, Wang C and Lu J: Carbon nanotubes promote neuron differentiation from human embryonic stem cells. Biochem Biophys Res Commun 384: 426-430, 2009.

25. Lu P, Li L, Liu G, van Rooijen N, Mukaida N and Zhang X: Opposite roles of CCR2 and CX3CR1 macrophages in alkali-induced corneal neovascularization. Cornea 28: 562-569, 2009.

26. Liu G, Lu P, Li L, Jin H, He X, Mukaida N and Zhang X: Critical role of SDF-1 $\alpha$-induced progenitor cell recruitment and macrophage VEGF production in the experimental corneal neovascularization. Mol Vis 17: 2129-2138, 2011.

27. Gyenge M, Amagase K, Kunimi S, Matsuoka R and Takeuchi K: Roles of pro-angiogenic and anti-angiogenic factors as well as matrix metalloproteinases in healing of NSAID-induced small intestinal ulcers in rats. Life Sci 93: 441-447, 2013.
28. Zhuang Z, Xiao-qin, Hu H, Tian SY, Lu ZJ, Zhang TZ and Bai YL: Down-regulation of microRNA-155 attenuates retinal neovascularization via the PI3K/Akt pathway. Mol Vis 21: 1173-1184, 2015

29. Kryczek I, Wei S, Szeliga W, Vatan L and Zou W: Endogenous IL-17 contributes to reduced tumor growth and metastasis. Blood 114: 357-359, 2009.

30. Nakashio A, Fujita $\mathrm{N}$ and Tsuruo T: Topotecan inhibits VEGF- and bFGF-induced vascular endothelial cell migration via downregulation of the PI3K-Akt signaling pathway. Int J Cancer 98: 36-41, 2002.

31. Ryu S, Lee JH and Kim SI: IL-17 increased the production of vascular endothelial growth factor in rheumatoid arthritis synoviocytes. Clin Rheumatol 25: 16-20, 2006.

32. Honorati MC, Neri S, Cattini L and Facchini A: Interleukin-17, a regulator of angiogenic factor release by synovial fibroblasts. Osteoarthritis Cartilage 14: 345-352, 2006.

33. Uno K, Hayashi H, Kuroki M, Uchida H, Yamauchi Y, Kuroki M and Oshima K: Thrombospondin-1 accelerates wound healing of corneal epithelia. Biochem Biophys Res Commun 315: 928-934, 2004.

34. Martínez A: A new family of angiogenic factors. Cancer Lett 236: 157-163, 2006

35. Sakaguchi I, Ikeda N, Nakayama M, Kato Y, Yano I and Kaneda K: Trehalose 6,6'-dimycolate (Cord factor) enhances neovascularization through vascular endothelial growth factor production by neutrophils and macrophages. Infect Immun 68: 2043-2052, 2000.

36. Edelman JL, Castro MR and Wen Y: Correlation of VEGF expression by leukocytes with the growth and regression of blood vessels in the rat cornea. Invest Ophthalmol Vis Sci 40: 1112-1123, 1999.

37. Lai CM, Spilsbury K, Brankov M, Zaknich T and Rakoczy PE: Inhibition of corneal neovascularization by recombinant adenovirus mediated antisense VEGF RNA. Exp Eye Res 75: 625-634, 2002.

38. Griffioen AW and Molema G: Angiogenesis: Potentials for pharmacologic intervention in the treatment of cancer, cardiovascular diseases, and chronic inflammation. Pharmacol Rev 52: 237-268, 2000.

39. Krstić J, Jauković A, Mojsilović S, Đorđević IO, Trivanović D, Ilić V, Santibañez JF and Bugarski D: In vitro effects of IL-17 on angiogenic properties of endothelial cells in relation to oxygen levels. Cell Biol Int 37: 1162-1170, 2013.

40. Wu LW, Mayo LD, Dunbar JD, Kessler KM, Baerwald MR, Jaffe EA, Wang D, Warren RS and Donner DB: Utilization of distinct signaling pathways by receptors for vascular endothelial cell growth factor and other mitogens in the induction of endothelial cell proliferation. J Biol Chem 275: 5096-5103, 2000

41. Dimmeler S and Zeiher AM: Akt takes center stage in angiogenesis signaling. Circ Res 86: 4-5, 2000.

42. Tsubaki M, Yamazoe Y, Yanae M, Satou T, Itoh T, Kaneko J, Kidera Y, Moriyama K and Nishida S: Blockade of the Ras/MEK/ERK and Ras/PI3K/Akt pathways by statins reduces the expression of bFGF, HGF and TGF- $\beta$ as angiogenic factors in mouse osteosarcoma. Cytokine 54: 100-107, 2011.

43. Bellacosa A, Testa JR, Staal SP and Tsichlis PN: A retroviral oncogene, akt, encoding a serine-threonine kinase containing an SH2-like region. Science 254: 274-277, 1991. 